\title{
Association Between Smoking and Postoperative Delirium in Surgical Patients With Pulmonary Hypertension: a Secondary Analysis of a Cohort Study
}

\section{Sai Zhou}

Changsha Medical University

\section{Shuqing Shi}

The Third Xiangya Hospital of Central South University

\section{Chang Xie}

The Third Xiangya Hospital of Central South University

Gong Chen ( $\square$ chengong86@csu.edu.cn)

The Third Xiangya Hospital of Central South University

\section{Research Article}

Keywords: smoking, postoperative delirium, pulmonary hypertension

Posted Date: December 22nd, 2021

DOI: https://doi.org/10.21203/rs.3.rs-1096523/v1

License: (c) (i) This work is licensed under a Creative Commons Attribution 4.0 International License.

Read Full License 


\section{Abstract}

Background: Previous studies have declared that smoking is a risk factor for postoperative delirium (POD), but others have inconsistent results. Up till now, the association between smoking and POD has not been verified. This study aims to investigate the relationship between smoking and POD in patients with pulmonary hypertension (PHTN) in the United States.

Methods: This study is a secondary analysis of a retrospective cohort study completed by Aalap C. et al. Patients with PHTN who underwent non-cardiac, non-obstetric surgery were enrolled in the original study. We further excluded the patients undergoing intracranial surgery and the patients with sepsis and perioperative stroke to avoid interference with POD assessment. The generalized linear model and generalized additive model were used to explore the relationship between smoking and POD.

Results: After adjusting the potential confounders (age, gender, BMI, poor functional status, PHTN severity, some comorbidities such as hypertension, angina, coronary artery disease, arrhythmia, COPD, asthma, diabetes and renal failure, length of surgery, open surgical approach, intraabdominal surgery, intrathoracic surgery, vascular surgery, some medications such as anticoagulant, antiplatelet, steroids, statin, and atropine, some inhalational anesthesia agent such as isoflurane and sevoflurane), a positive relationship was found between smoking status and POD (OR=5.61, 95\% Cl: 1.14 to 27.51, $P=0.0334$ ). In addition, the curvilinear relationship between smoking burden (pack-years) and POD is close to a linear relationship.

Conclusion: Smoking shows a positive correlation with POD in patients with PHTN. Surgical individuals need to prevent POD especially those with a heavy smoking burden.

\section{Introduction}

Postoperative delirium (POD) is a common neurological complication after surgery[1]. The incidence of POD is around $11-51 \%$ in surgical patients and increases with elderly individuals[2]. It extends the length of hospital stay by an average of 2-3 days and increases the postoperative 30-day mortality by 7-10\%[3]. Therefore, it brings a heavy burden to individuals, families, and societies. However, there is a lack of effective therapeutics to treat POD. Currently, accurate identification of risk factors is the mainstay for POD prevention.

Many risk factors contribute to POD such as old age, diabetes, COPD, and pulmonary circulation disorders $[4,5]$. Tobacco smoking causes many cardiovascular diseases such as hypertension, atherosclerosis, and atrial fibrillation, contributing to neuronal damage[6-8]. In addition, smoking is also a significant risk factor associated with neuropsychiatric illness including POD. However, some studies reported that smoking did not significantly influence POD incidence[9-11]. Up till now, the association between smoking and POD has not been verified. 
The current study conducted a secondary data analysis of a published paper to explore how smoking affects POD[12]. In the original article, the authors studied the correlation between self-reported functional status and postoperative outcomes in non-cardiac surgical patients with pulmonary hypertension (PHTN). Interestingly, the actual data contained information on smoking and POD. Using this information, we aim to explore the association between tobacco smoking and POD in PHTN patients. We hypothesis that smoking patients with PHTN would have a higher risk of POD.

\section{Methods}

\section{Data source}

We obtain data from the "DATADRYAD" database (datadryad.org), allowing users to download raw data for free. Following the Dryad Terms of Service, we quoted the Dryad data package in this research. (Shah, Aalap C. et al. (2019), Data from Self-reported functional status predicts postoperative outcomes in noncardiac surgery patients with pulmonary hypertension, Dryad, Dataset, https://doi.org/10.5061/dryad.9236ng5). The variables in this database file include the following: age, gender, BMI, ASA classification, self-reported functional status, PHTN severity classification, length of surgery, surgical approach, comorbidities, medications, inhalational agents, tobacco smoking, delirium and so on.

\section{Ethics Approval and Consent to Participate}

The participation consent and the new ethics approval were not applicable for this study since this is a secondary analysis of original research. The original authors (Aalap C. Shah et al.) had provided the ethics permission from the University of Washington[12].

\section{Study population}

Aalap C. Shah et al. conducted a retrospective cohort study at the University of Washington Medical Center from April 2007 to September 2013. In the original research, patients who underwent elective noncardiac, non-obstetric surgery were recruited. Exclusion criteria include 1) PHTN was diagnosed after the operation; 2) The patient was admitted more than 24 hours before the operation; 3) The preoperative anesthesia clinic visit data including the self-reported functional status was not available, or 4) The operation was canceled before or after anesthesia. A total of 550 patients were recruited and selected in the original investigation. To avoid interference with POD assessment, we further excluded patients undergoing intracranial surgery and patients with sepsis and perioperative stroke. Finally, 539 patients were included in our study.

\section{Data collection}

According to the description of the original paper[12], the actual data was derived from hospital progress records and discharge summary records. Demographic information, including age, sex, BMI, and selfreported functional status were collected. Documented comorbidities include cardiovascular disease 
(myocardial infarction, arrhythmia, congestive heart failure), lung disease (asthma and COPD), diabetes, and chronic kidney disease. PHTN severity was also recorded according to the WHO classification of PHTN subtypes. Some perioperative medications and factors related to surgery and anesthesia were also collected. Smoking-related records include whether they smoked or not, current smoking status, and smoking burden (pack-years). POD was collected from the nursing records.

\section{Statistical analysis}

Baseline characteristics for different groups of smoking status and burdens were reported. Continuous variables are expressed as mean \pm SD or median (IQR), depending on whether it is the normal distribution. Categorical variables are expressed as frequency or percentage. One-way ANOVA or Kruskal Wallis $\mathrm{H}$ test is used for continuous data, and the chi-square test is used for categorical data to explore statistical differences between different groups. We used never-smokers as a reference to estimate ORs with $95 \%$ confidence interval $(\mathrm{Cl})$ by multivariable logistic regression adjusted for several confounding factors. Following the STROBE recommendations, the unadjusted, minimally adjusted, and fully adjusted analyses are all exhibited in this paper. The covariances in fully adjusted analyses include age, gender, $\mathrm{BMI}$, poor functional status, PHTN severity, some comorbidities such as hypertension, angina, coronary artery disease, arrhythmia, COPD, asthma, diabetes and renal failure, length of surgery, open surgical approach, intraabdominal surgery, intrathoracic surgery, vascular surgery, some medications such as anticoagulant, antiplatelet, steroids, statin, and atropine, some inhalational anesthesia agent such as isoflurane and sevoflurane. Whether to adjust the covariances in the minimally adjusted model was determined by the following principle. After being added to this model, the adjusted covariance should change the matching odds ratio by at least $10 \%[13]$. In addition, a generalized additive model (GAM) was also used to identify the curve relationship. All analyses were performed using software packages $\mathrm{R}$ (http://www.R-project.org, The R Foundation) and EmpowerStats (http://www.empowerstats.com, X\&Y Solutions, Inc., Boston, MA). Two-sized $P$ values less than 0.05 are considered statistically significant.

\section{Results}

\section{Baseline characteristics of patients}

There were 271 never-smokers and 268 ever-smokers in this cohort. Baseline characteristics are listed in Table1. The age of the smoker group is slightly higher than the age of the never-smoker group. Compared with the never-smokers, smokers had a significantly higher ASA classification and a significantly higher percentage of arrhythmia and COPD. Compared with the never-smokers, more patients in the smoking group received statin, steroids, and inhalational agents. Baseline characteristics of different smoking burden groups (pack-years) are listed in TableS1.

Table 1: Baseline characteristics 


\begin{tabular}{|c|c|c|c|c|}
\hline Variables & $\begin{array}{l}\text { Never Smoker } \\
(n=271)\end{array}$ & $\begin{array}{l}\text { Smoker } \\
(n=268)\end{array}$ & $\begin{array}{l}\text { Standardize } \\
\text { diff. }\end{array}$ & $\begin{array}{l}P \text { - } \\
\text { value }\end{array}$ \\
\hline Age, years [mean $(S D)$ ] & $58.88(15.07)$ & 61.96 (12.69) & $\begin{array}{l}0.22(0.05 \\
0.39)\end{array}$ & 0.059 \\
\hline Male Gender & $140(51.66 \%)$ & $151(56.34 \%)$ & $\begin{array}{l}0.09(-0.07 \\
0.26)\end{array}$ & 0.275 \\
\hline$B M I, \mathrm{~kg} / \mathrm{m}^{2}[$ mean $(S D)]$ & $32.05(13.43)$ & $31.46(10.51)$ & $\begin{array}{l}0.05(-0.12 \\
0.22)\end{array}$ & 0.469 \\
\hline $\begin{array}{l}\text { Poor Functional Status (<4 } \\
\text { MET) }\end{array}$ & $133(49.08 \%)$ & $137(51.12 \%)$ & $\begin{array}{l}0.04(-0.13 \\
0.21)\end{array}$ & 0.635 \\
\hline ASA Classification & & & $\begin{array}{l}0.27(0.10 \\
0.44)\end{array}$ & 0.009 \\
\hline II & $28(10.33 \%)$ & $15(5.60 \%)$ & & \\
\hline III & $192(70.85 \%)$ & $177(66.04 \%)$ & & \\
\hline IV & $51(18.82 \%)$ & $76(28.36 \%)$ & & \\
\hline PHTN Severity Classification & & & $\begin{array}{l}0.11(-0.07 \\
0.28)\end{array}$ & 0.479 \\
\hline Mild & $118(46.09 \%)$ & $108(41.38 \%)$ & & \\
\hline Moderate & $113(44.14 \%)$ & $129(49.43 \%)$ & & \\
\hline Severe & $25(9.77 \%)$ & $24(9.20 \%)$ & & \\
\hline \multicolumn{5}{|l|}{ Surgical Characteristics } \\
\hline $\begin{array}{l}\text { Length of Surgery [median } \\
(I Q R)]\end{array}$ & $\begin{array}{l}77.00(34.00- \\
141.00)\end{array}$ & $\begin{array}{l}94.00(36.75- \\
159.25)\end{array}$ & $\begin{array}{l}0.14(-0.03 \\
0.31)\end{array}$ & 0.168 \\
\hline Open Surgical Approach & $153(56.46 \%)$ & $131(48.88 \%)$ & $\begin{array}{l}0.15(-0.02 \\
0.32)\end{array}$ & 0.078 \\
\hline Intraabdominal & $52(19.19 \%)$ & $60(22.39 \%)$ & $\begin{array}{l}0.08(-0.09 \\
0.25)\end{array}$ & 0.360 \\
\hline Intrathoracic & $14(5.17 \%)$ & $13(4.85 \%)$ & $\begin{array}{l}0.01(-0.15 \\
0.18)\end{array}$ & 0.867 \\
\hline Vascular & $6(2.21 \%)$ & $13(4.85 \%)$ & $\begin{array}{l}0.14(-0.03 \\
0.31)\end{array}$ & 0.097 \\
\hline \multicolumn{5}{|l|}{ Comorbidities } \\
\hline Systemic Hypertension & $172(63.47 \%)$ & $187(69.78 \%)$ & $\begin{array}{l}0.13(-0.03 \\
0.30)\end{array}$ & 0.121 \\
\hline
\end{tabular}




\begin{tabular}{|c|c|c|c|c|}
\hline Coronary Artery Disease & $88(32.84 \%)$ & $93(34.83 \%)$ & $\begin{array}{l}0.04(-0.13, \\
0.21)\end{array}$ & 0.626 \\
\hline Arrhythmia & $136(50.18 \%)$ & 105 (39.18\%) & $\begin{array}{l}0.22(0.05 \\
0.39)\end{array}$ & 0.010 \\
\hline Angina & $16(5.90 \%)$ & $23(8.58 \%)$ & $\begin{array}{l}0.10(-0.07 \\
0.27)\end{array}$ & 0.230 \\
\hline Asthma & $44(16.24 \%)$ & $31(11.61 \%)$ & $\begin{array}{l}0.13(-0.04 \\
0.30)\end{array}$ & 0.121 \\
\hline COPD & $10(3.70 \%)$ & $61(22.85 \%)$ & $\begin{array}{l}0.59(0.42, \\
0.76)\end{array}$ & $<0.001$ \\
\hline Diabetes & $77(28.41 \%)$ & $78(29.21 \%)$ & $\begin{array}{l}0.02(-0.15 \\
0.19)\end{array}$ & 0.838 \\
\hline Renal Failure & $75(27.68 \%)$ & $60(22.39 \%)$ & $\begin{array}{l}0.12(-0.05 \\
0.29)\end{array}$ & 0.157 \\
\hline \multicolumn{5}{|l|}{ Medications } \\
\hline Anticoagulant & $82(30.26 \%)$ & 65 (24.25\%) & $\begin{array}{l}0.14(-0.03, \\
0.30)\end{array}$ & 0.118 \\
\hline Antiplatelet & $9(3.32 \%)$ & $9(3.36 \%)$ & $\begin{array}{l}0.00(-0.17 \\
0.17)\end{array}$ & 0.981 \\
\hline Statin & $110(40.59 \%)$ & $132(49.25 \%)$ & $\begin{array}{l}0.17(0.01 \\
0.34)\end{array}$ & 0.043 \\
\hline Steroids & $39(14.39 \%)$ & $61(22.76 \%)$ & $\begin{array}{l}0.22(0.05 \\
0.39)\end{array}$ & 0.012 \\
\hline Atropine & $2(0.74 \%)$ & $3(1.13 \%)$ & $\begin{array}{l}0.04(-0.13 \\
0.21)\end{array}$ & 0.683 \\
\hline Inhalational Agents & $137(50.93 \%)$ & $168(63.40 \%)$ & $\begin{array}{l}0.25(0.08 \\
0.42)\end{array}$ & 0.004 \\
\hline Isoflurane & $6(2.21 \%)$ & $12(4.48 \%)$ & $\begin{array}{l}0.13(-0.04, \\
0.30)\end{array}$ & 0.144 \\
\hline Sevoflurane & $111(40.96 \%)$ & $136(50.75 \%)$ & $\begin{array}{l}0.20(0.03 \\
0.37)\end{array}$ & 0.023 \\
\hline Delirium & $5(1.85 \%)$ & $11(4.10 \%)$ & $\begin{array}{l}0.13(-0.04, \\
0.30)\end{array}$ & 0.122 \\
\hline Mortality & $3(1.11 \%)$ & $4(1.49 \%)$ & $\begin{array}{l}0.03(-0.13 \\
0.20)\end{array}$ & 0.724 \\
\hline
\end{tabular}

BMI body mass index, MET metabolic equivalent of task, ASA American Society of Anesthesiologists, PHTN pulmonary hypertension, IQR interquartile range, COPD chronic obstructive pulmonary disease 


\section{The relationship between the smoking status and POD}

The univariate analysis showed that only age and intrathoracic surgery were correlated with POD (TableS2). To accurately evaluate the association between smoking status and POD, we exhibited the unadjusted and adjusted models in Table2. In the unadjusted model, tobacco smoking did not significantly correlate with $\mathrm{POD}(\mathrm{OR}=2.28,95 \% \mathrm{Cl}: 0.78$ to $6.64, P=0.1320)$. However, smoking showed a positive correlation with $\mathrm{POD}$ in the minimally adjusted (OR=4.06, 95\% $\mathrm{Cl}: 1.26$ to $13.07, P=0.0189)$ and fully adjusted models (OR=5.61, $95 \% \mathrm{Cl}$ : 1.14 to $27.51, P=0.0334)$.

Table 2: Relationship between smoking status and POD in different models

\begin{tabular}{|c|c|c|c|}
\hline Variables & $\begin{array}{l}\text { Unadjusted model (OR } \\
95 \% \mathrm{Cl} P \text { ) }\end{array}$ & $\begin{array}{l}\text { Minimally adjusted model } \\
(O R 95 \% \mathrm{Cl} P)\end{array}$ & $\begin{array}{l}\text { Fully adjusted model (OR } \\
95 \% \mathrm{Cl} P)\end{array}$ \\
\hline \multicolumn{4}{|l|}{$\begin{array}{l}\text { Tobacco } \\
\text { Smoking }\end{array}$} \\
\hline $\begin{array}{l}\text { Never } \\
\text { smoker }\end{array}$ & ref & ref & ref \\
\hline Smoker & $\begin{array}{l}2.28(0.78,6.64) \\
0.1320\end{array}$ & $4.06(1.26,13.07) 0.0189$ & $5.61(1.14,27.51) 0.0334$ \\
\hline
\end{tabular}

Unadjusted model: We do not adjust for other covariances

Minimally adjusted model: We adjust for COPD, coronary artery disease, vascular surgery, systemic hypertension

Fully adjusted model: We adjust for age, gender, BMI, poor functional status, PHTN severity class, length of surgery, open surgical approach, intraabdominal surgery, intrathoracic surgery, vascular surgery, COPD, asthma, arrhythmia, systemic hypertension, angina, coronary artery disease, renal failure, diabetes, steroids, anticoagulant, atropine, antiplatelet, statin, anesthesia inhalational agents, isoflurane, sevoflurane

\section{The relationship between the smoking burden and POD}

Next, we compared the incidence of POD in different smoking burden groups. Compared with neversmokers (smoking burden $=0$ ), heavy smokers (smoking burden>50) show a significant increase in POD incidence both in the unadjusted and adjusted models (Table3).

Table 3: Relationship between smoking burden and POD in different models 


\begin{tabular}{|c|c|c|c|}
\hline Variables & $\begin{array}{l}\text { Unadjusted model (OR } \\
95 \% \mathrm{Cl} P \text { ) }\end{array}$ & $\begin{array}{l}\text { Minimally adjusted model (OR } \\
95 \% \mathrm{Cl} P)\end{array}$ & $\begin{array}{l}\text { Fully adjusted model (OR } \\
95 \% \mathrm{Cl} P \text { ) }\end{array}$ \\
\hline \multicolumn{4}{|l|}{$\begin{array}{l}\text { Pack- } \\
\text { years }\end{array}$} \\
\hline 0 & ref & ref & ref \\
\hline $\begin{aligned} & >0 \\
< & =50\end{aligned}$ & $1.75(0.50,6.14) 0.3823$ & $3.16(0.48,20.82) 0.2326$ & $3.63(0.44,29.78) 0.2303$ \\
\hline $\begin{aligned} & >50, \\
< & =100\end{aligned}$ & $\begin{array}{l}3.32(0.62,17.85) \\
0.1611\end{array}$ & $15.59(1.29,188.07) 0.0307$ & $\begin{array}{l}12.30(0.74,204.90) \\
0.0803\end{array}$ \\
\hline$>100$ & $\begin{array}{l}26.60(2.06,343.51) \\
0.0120\end{array}$ & $58.97(0.87,3990.03) 0.0580$ & $\begin{array}{l}90.08(0.79,10266.01) \\
0.0625\end{array}$ \\
\hline
\end{tabular}

Unadjusted model: We do not adjust for other covariances

Minimally adjusted model: We adjust for age, gender, PHTN severity, length of surgery, open surgical approach, intrathoracic surgery, vascular surgery, COPD, asthma, coronary artery disease, angina, systemic hypertension, anticoagulant, anesthesia inhalational agents, isoflurane, sevoflurane Fully adjusted model: We adjust for age, gender, BMI, poor functional status, PHTN severity, length of surgery, open surgical approach, intraabdominal surgery, intrathoracic surgery, vascular surgery, COPD, asthma, arrhythmia, systemic hypertension, angina, coronary artery disease, renal failure, diabetes, steroids, anticoagulant, atropine, antiplatelet, statin, anesthesia inhalational agents, isoflurane, sevoflurane

Since the smoking burden is continuous data, we explore the curve relationship between pack-years and POD. After adjusting several cofounders, we found a curvilinear relationship between smoking burden and POD is close to a linear relationship (Fig.1).

\section{Discussion}

This study aims to explore the relationship between smoking and POD in PHTN patients. As shown in the adjusted model, smoking is positively correlated with POD. In addition, we also found the curvilinear relationship between pack-years of smoking and POD.

We performed a PubMed search using both the keywords "smoking" and "postoperative delirium." As of October 2021, 52 scientific papers have been retrieved from this database, but only eight are related to our research. In those studies, smoking was listed as a risk factor for POD in patients with different types of surgery. However, they did not sufficiently adjust the potential confounders for the association between smoking and POD. These confounders include COPD, coronary artery disease, hypertension and so on. Therefore, their conclusions are limited because the aforementioned confounding factors are closely 
related to smoking and POD. The present study is the first to verify the association between smoking and POD to the best of our knowledge.

Our research has several advantages. First, the generalized linear model and the generalized additive model (GAM) were used to clarify the relationships between smoking and POD, which will help us better discover the actual connection between exposure and results. Second, we used strict statistical adjustments to minimize residual confounding. Although previous studies have suggested that smoking is a risk factor for POD, they have not adjusted the necessary confounding factors. We selected 26 possible confounding factors from the original data table and screened the covariates according to the methods provided in the previous literature[13] to determine the precisely adjusted confounding. Third, in the selection of covariates, continuous variables and categorical variables are used to verify the association between smoking and POD.

Our research has some limitations. First, this study is a retrospective cohort study. Therefore, prospective studies may be needed for verification in the future. Second, because the study population only includes Americans with PHTN, it may not be generalized to people from other countries and patients with other diseases. Third, we cannot observe the correlation between quitting smoking and POD due to raw data limitations.

\section{Conclusion}

Smoking shows a positive correlation with POD in patients with PHTN. Surgical individuals need to prevent POD especially those with the heavy smoking burden.

\section{Declarations}

\section{Ethics approval and consent to participate}

All clinical studies described in the manuscript were carried out following the Declaration of Helsinki promulgated by the National Institute of Health. The participation consent form was not applicable for this study because this is a retrospective analysis of data reuse, and all the patients in the original data are anonymous. We did not provide the new ethics approval either since the original authors (Aalap C. Shah et al.) had obtained the permission of the ethics when conducting the original research.

\section{Consent for publication}

Not applicable

\section{Availability of data and materials}

The data used to support the findings of this study are available from the DATADRYAD website.

\section{Competing interests}


There are no competing interests regarding the publication of this paper.

\section{Funding}

This work was supported by the New Xiangya Talent Project of the Third Xiangya Hospital of Central South University [grant number JY201701]. The funders had no role in study design, data collection and analysis, decision to publish, or manuscript preparation.

\section{Authors' contributions}

G.C. and S.Z. carried out the studies and drafted the manuscript. S.S. and S.Z. performed the statistical analysis and participated in its design. C.X. helped to draft the manuscript. All authors read and approved the final manuscript.

\section{Acknowledgment}

Not applicable

\section{References}

1. Saczynski JS, Marcantonio ER, Quach L, Fong TG, Gross A, Inouye SK, Jones RN: Cognitive trajectories after postoperative delirium. N Engl J Med 2012, 367(1):30-39.

2. Inouye SK, Westendorp RGJ, Saczynski JS: Delirium in elderly people. The Lancet 2014, 383(9920):911-922.

3. Jin Z, Hu J, Ma D: Postoperative delirium: perioperative assessment, risk reduction, and management. Br J Anaesth 2020, 125(4):492-504.

4. Yang Q, Wang J, Huang $X, X u$ Y, Zhang Y: Incidence and risk factors associated with postoperative delirium following primary elective total hip arthroplasty: a retrospective nationwide inpatient sample database study. BMC Psychiatry 2020, 20(1):343.

5. Wu J, Yin Y, Jin M, Li B: The risk factors for postoperative delirium in adult patients after hip fracture surgery: a systematic review and meta-analysis. Int J Geriatr Psychiatry 2021, 36(1):3-14.

6. Dikalov S, Itani H, Richmond B, Vergeade A, Rahman SMJ, Boutaud O, Blackwell T, Massion PP, Harrison DG, Dikalova A: Tobacco smoking induces cardiovascular mitochondrial oxidative stress, promotes endothelial dysfunction, and enhances hypertension. Am J Physiol Heart Circ Physiol 2019, 316(3):H639-H646.

7. Wang Z, Wang D, Wang Y: Cigarette Smoking and Adipose Tissue: The Emerging Role in Progression of Atherosclerosis. Mediators Inflamm 2017, 2017:3102737.

8. Watanabe I: Smoking and risk of atrial fibrillation. J Cardiol 2018, 71(2):111-112.

9. Bosmak FS, Gibim PT, Guimaraes S, Ammirati AL: Incidence of delirium in postoperative patients treated with total knee and hip arthroplasty. Rev Assoc Med Bras (1992) 2017, 63(3):248-251. 
10. He Z, Cheng H, Wu H, Sun G, Yuan J: Risk factors for postoperative delirium in patients undergoing microvascular decompression. PLoS One 2019, 14(4):e0215374.

11. Large MC, Reichard C, Williams JT, Chang C, Prasad S, Leung Y, DuBeau C, Bales GT, Steinberg GD: Incidence, risk factors, and complications of postoperative delirium in elderly patients undergoing radical cystectomy. Urology 2013, 81(1):123-128.

12. Shah AC, Ma K, Faraoni D, Oh DCS, Rooke GA, Van Norman GA: Self-reported functional status predicts post-operative outcomes in non-cardiac surgery patients with pulmonary hypertension. PLOS One 2018, 13(8):e0201914.

13. Kernan WN, Viscoli CM, Brass LM, Broderick JP, Brott T, Feldmann E, Morgenstern LB, Wilterdink JL, Horwitz RI: Phenylpropanolamine and the risk of hemorrhagic stroke. N Engl J Med 2000, 343(25):1826-1832.

\section{Figures}




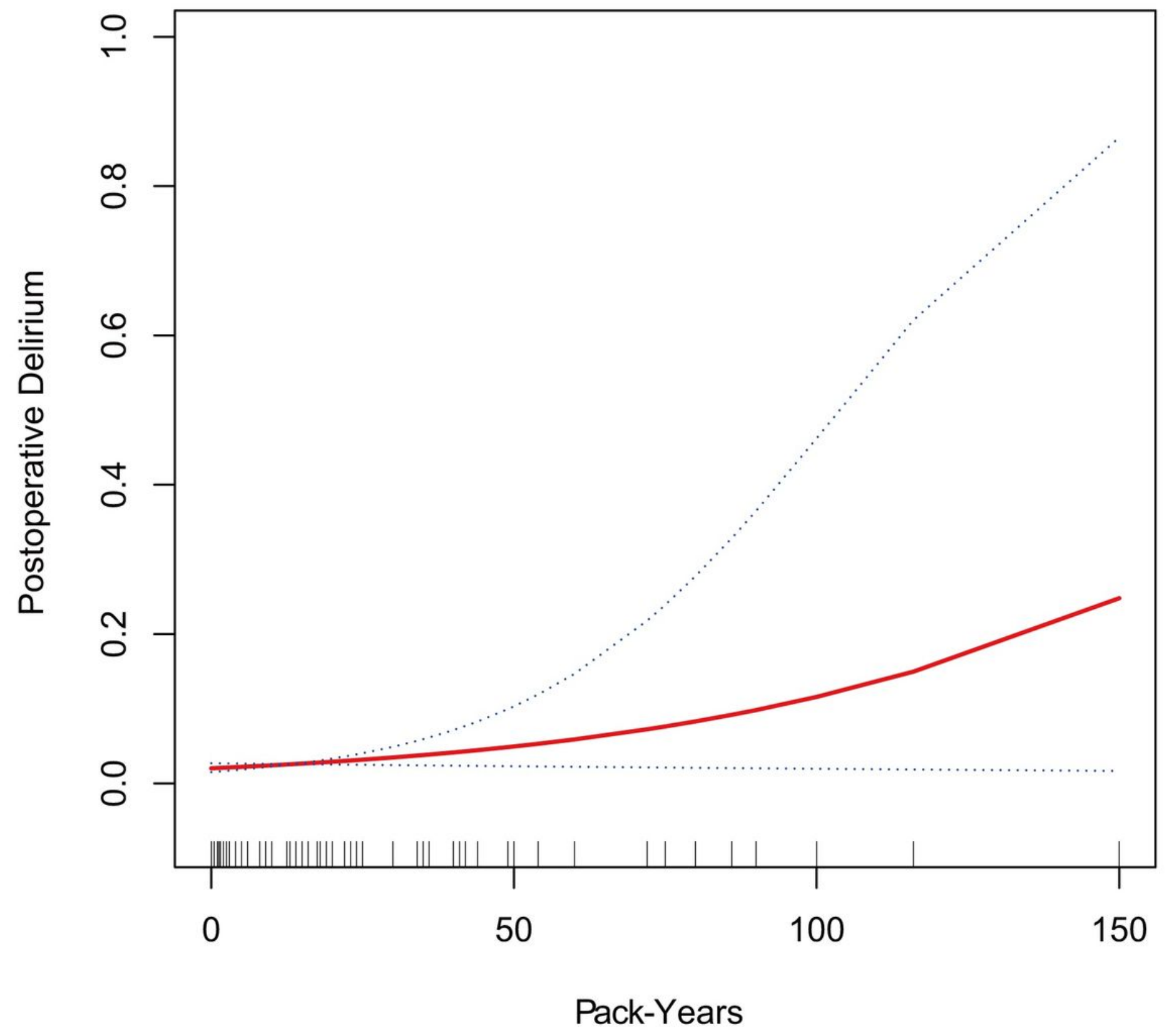

Figure 1

The relationship between smoking burden and postoperative delirium. A curvilinear relationship between smoking burden and POD is close to a linear relationship after adjusting for age, PHTN severity, COPD, angina, coronary artery disease, length of surgery, intrathoracic surgery, and anesthesia inhalational agents.

\section{Supplementary Files}

This is a list of supplementary files associated with this preprint. Click to download.

- TableS1.docx 
- Tables2.docx

- STROBEchecklist.docx 